\title{
Survey on academic medicine culture, enablers \& barriers in a newly formed academic department in Singapore
}

\author{
Kok Hian Tan*1,2,3, Mor Jack Ng${ }^{1}$, Wan Shi Tey ${ }^{1}$, Hak Koon Tan ${ }^{1,4}$, Bernard Chern ${ }^{1,2}$ \\ ${ }^{1}$ SingHealth Duke-NUS OBGYN Academic Clinical Program, Singapore \\ ${ }^{2}$ Division of Obstetrics \& Gynaecology, KK Women's and Children's Hospital, Singapore \\ ${ }^{3}$ SingHealth Duke-NUS Joint Office of Academic Medicine, Singapore \\ ${ }^{4}$ Department of Obstetrics \& Gynaecology, Singapore General Hospital, Singapore
}

Received: April 26, 2016

DOI: $10.5430 /$ jha.v5n5p30
Accepted: July 3, 2016

Online Published: July 8, 2016

\begin{abstract}
Objective: A positive culture of academic medicine is important for improving healthcare, research and medical education. This study seeks to assess academic medicine culture, enablers and barriers with a multi-dimensional structured survey, in a newly formed academic department from the perspectives of faculty and staff.

Methods: Thirteen dimensions relating to academic medicine culture were identified after focused group discussions. Each dimension contains four relevant questions with answers on a 5-point Likert scale. This web-based questionnaire survey was conducted for senior and junior physicians within SingHealth Duke-NUS Obstetrics \& Gynecology (OBGYN) academic department in 2011. This unit was started within the academic medical centre formed by SingHealth, and Duke-NUS which is a medical school jointly established by Duke University and National University of Singapore (NUS). Gaps were identified and addressed with various initiatives. A second survey in 2012 and a third survey in 2013 were conducted to assess the change in culture.

Results: In the first survey, the top three favorable dimensions (highest percentage of composite positive response) were: Supervisor and Departmental Support for Academic Medicine (64.0\%); Academic Faculty Development (57.9\%); and Communications \& Feedbacks on Academic Medicine (57.3\%). The bottom three dimensions which were areas for improvements were: Academic Clinical Staffing Issue (23.8\%); Relating Clinical Service to Research \& Education (33.2\%); and Academic Teamwork across Institutions (36.3\%). In the second survey, there was overall improvement for 12 of the 13 dimensions. In the third survey, there was overall improvement for all the 13 dimensions compared to the first survey.

Conclusions: There were positive changes, likely contributed by initiatives within the department to engage staff and to address gaps in various aspects of academic medicine culture.
\end{abstract}

Key Words: Academic medicine, Culture change, Teamwork, Organizational learning, Faculty development

\section{INTRODUCTION}

Academic medicine culture refers to the belief, perception, attitudes and values that exist in academic medicine insti- tutions and held by those working within these academic institutions. A positive culture of academic medicine is important for medical education. ${ }^{[1]}$ While there are surveys of

*Correspondence: Kok Hian Tan, Prof; Email: tan.kok.hian@ singhealth.com.sg; Address: Department of Maternal Fetal Medicine, KK Women's \& Children's Hospital, 100 Bukit Timah Road, 229899, Singapore. 
culture in clinical medicine like patient safety culture, ${ }^{[2-4]}$ there are currently few surveys on academic medicine culture and its enablers and barriers.

Previous studies undertaken on the culture of Academic Medicine dealt on various interesting aspects including those on relating academic medicine culture to gender differences and alignment of individual with institutional values. ${ }^{[5,6]}$ Valantine \& Sandborg argued in their study that culture of academic medicine must change to one in which there are flexibility and work-life integration to eliminate the gender leadership gap. ${ }^{[6]}$ Pololi et al. showed an academic medicine culture with negative relational attributes among faculty and leadership such as disconnection, competitive individualism, undervaluing of humanistic qualities, and the erosion of trust can affect medical faculty vitality, professionalism, and general productivity and retention. ${ }^{[7]}$

There has been no study which has examined change in culture in a newly formed academic department. Such a study can provide information on the needs, enablers and barriers as well as can provide some directions for the newly formed department to proceed in the academic journey.

SingHealth is the largest healthcare cluster in Singapore. Through SingHealth's strategic partnership in Academic Medicine with the Duke-NUS Graduate Medical School (jointly established by Duke University and the National University of Singapore since 2005), the OBGYN academic department or Academic Clinical Program (OBGYN ACP) was officially rolled out in May 2011. OBGYN ACP was one of the first academic departments to be launched in SingHealth from its original clinical departments. It comprised faculty, residents and physicians of Department of OBGYN in Singapore General Hospital and Division of OBGYN in KK Women's and Children's Hospital. The formation of this model is consistent with practices in most academic medical centers in the world, where partnership between a healthcare provider and a university provides a synergistic framework in improving healthcare, research and medical education.

This study seeks to assess academic medicine culture using a multi-dimensional structured survey in this newly formed academic department. It also seeks to assess differences of perceptions of junior and senior faculty/physicians on academic medicine culture, its enablers and barriers.

\section{MethodS}

In the transition from a predominantly clinical unit and the formation of an academic unit, dialogues/feedback sessions between the leadership and faculty \& staff on the culture, the barriers and enablers, were set up by the department. Various aspects of the culture, enablers and barriers were identified from the feedbacks. These were felt to be important aspects of culture, culture enablers and barriers and could affect the transition towards a more positive academic culture in our environment. These feedbacks were then discussed at focus groups by the leaders and senior staff. Various conceptual frameworks or models ${ }^{[5-14]}$ concerning enablers and barriers of academic medicine and faculty development were also explored during the focus group discussions.

Dimensions relating to the culture, barriers and enablers of academic medicine were identified through focused group discussions based on the feedbacks. Thirteen dimensions were deemed pertinent. These dimensions were felt by the leadership of the department to be important for the transition to academic unit to survey and to work on. Various surveys relating to holistic overview of clinical medicine ${ }^{[2-4,15]}$ were studied. A survey questionnaire was developed based on the ground feedbacks and focus group discussions as mentioned earlier, to assess the perception of staff and faculty in the 13 dimensions identified as follows (see Table 1):

Table 1. Thirteen dimensions

1. Leadership \& Management Support for Academic Medicine
2. Supervisor \& Departmental Support for Academic Medicine
3. Communications \& Feedbacks on Academic Medicine
4. Learning \& Innovation Environment
5. Academic Scholarly Activities
6. Academic Faculty Development
7. Academic Teamwork within Institution/Hospital
8. Academic Teamwork across Institutions
9. Relating Clinical Service to Research and Education
10. Academic Clinical Staffing
11. Satisfaction \& Remuneration for Academic Medicine
12. Organizational Learning
13. Overall Perceptions of Academic Medicine

Survey questions were formulated based on these 13 aspects (4 questions each) in a 5-point Likert Scale (see Table 2).

The survey was first introduced on 11 November 2011 and conducted in OBGYN ACP. Gaps were identified and addressed with various initiatives. A second survey and a third survey were conducted in December 2012 and December 2013.

Senior physician faculty were defined as those staff who attained specialist qualification and had been on the register of the Specialist Accreditation Board. Junior physicians were physician staff working in the organization who had not attained specialist qualification. The study was reviewed and given Exempt status by the SingHealth Centralised Institutional Review Board (CIRB). 
Table 2. Survey questionnaire of academic medicine culture, enablers \& barriers

\begin{tabular}{|c|c|}
\hline 1) & Leadership \\
\hline a. & Leadership tangibly show that education and research are top priorities. \\
\hline b. & Leadership promote an environment that is conducive to education and research. \\
\hline c. & $\begin{array}{l}\text { Leadership and administration appear to be keen on education and research only when pushed by a higher authority (i.e. } \\
\text { sporadically). }\end{array}$ \\
\hline d. & Leadership and administration do not offer adequate resources necessary for education and research to thrive. \\
\hline 2) & Supervision \\
\hline a. & My superior gives encouragement or positive feedback when work relating to education or research is performed \\
\hline b. & My superior fails to consider or notice educational or research issues/problems that occur repeatedly. \\
\hline c. & $\begin{array}{l}\text { Whenever clinical workload increases, my superior puts a priority on that work, even if it means skipping educational and/or } \\
\text { research activities }\end{array}$ \\
\hline d. & My superior genuinely considers ideas for improving education and research. \\
\hline 3) & Communications \& Feedback \\
\hline a. & We are updated about educational and research changes in our department (e.g. policy, practice etc.) \\
\hline b. & We are encouraged to provide feedback about educational or research changes that will be or are put into place. \\
\hline c. & We do not usually discuss on ways to improve education or research issues in our work. \\
\hline d. & Our feedbacks are acknowledged and acted upon. \\
\hline 4) & Academic Environment \\
\hline a. & We feel free to question current protocols/practices at our institution. \\
\hline b. & We do not have time to think about educational or research aspects of a clinical issue. \\
\hline c. & New or innovative ideas are encouraged in this institution. \\
\hline d. & New learning or teaching methods are not welcomed in this institution \\
\hline 5) & Scholarly Activities \\
\hline a. & Opportunities to participate in academic events, including education \& research activities (meetings, conferences etc.) are limited. \\
\hline b. & Staff look forward to participating in research and/or education activities. \\
\hline c. & Staff have time to attend these scholarly activities. \\
\hline d. & Staff benefit from these scholarly activities. \\
\hline 6) & Professional Development \\
\hline a. & There are ample opportunities and courses for faculty development for staff \\
\hline b. & Securing protected time for faculty professional development and learning is problematic in this hospital \\
\hline c. & Faculty development is important for professional growth \\
\hline d. & An academic appointment is not important to me. \\
\hline 7) & Intra-Institution Teamwork \\
\hline a. & Departments within this institution do not collaborate well with respect to educational and research activities. \\
\hline b. & Teamwork is evident during peak periods where timelines are tight for academic work. \\
\hline c. & Staff provide help \& support to each other in academic work (i.e. research and/or education). \\
\hline d. & Within the institution, people treat each other’s academic work with regard and due respect. \\
\hline 8) & Inter-Institution Teamwork \\
\hline a. & We have sufficient collaboration with other institutions for research and education activities. \\
\hline b. & Institutions do not coordinate effectively with each other as it relates to academic medicine. \\
\hline c. & There is good teamwork across various institutions. \\
\hline d. & It is not easy to work with staff from other institutions \\
\hline 9) & Service \& Academic Balance \\
\hline a. & Patient care or service continuity is not lost when a staff member performs research or education. \\
\hline b. & Problems often occur in balancing service with education and research across this hospital \\
\hline c. & Protected time for research is problematic for staff in this institution \\
\hline d. & Protected time for teaching is problematic for staff in this institution \\
\hline 10) & Staff Matters \\
\hline a. & Staff often have to "fire fight” or put up with unexpected emergencies in our work. \\
\hline b. & We employ more temps/locum staff than is optimal. \\
\hline c. & We have sufficient staff to cope with the department's clinical and academic workload. \\
\hline d. & Staff in this department work longer hours than is optimal. \\
\hline
\end{tabular}


Table 2. (continued.)

\begin{tabular}{|ll|}
\hline 11) & Job Satisfaction \\
a. & Staff believes research and education are necessary in addition to providing clinical service. \\
b. & Job satisfaction as a clinician scientist/investigator or clinician educator can be the same or higher than that of a clinician. \\
c. & Staff worry that efforts made in education will be rewarded less than service. \\
d. & Staff worry that efforts made in research will be rewarded less than service. \\
12) & Institution Learning \\
a. & We are constantly looking for ways to improve any aspect of academic medicine (i.e. research, education, evidenced based service). \\
b. & Doing so has brought about positive changes at this institution. \\
c. & We study/review the effectiveness of implementing change as it relates to the improvement of research, education and service at our \\
& institution. \\
d. & Staff will freely speak up if they see something that may negatively affect research, education or service. \\
13) & Overall \\
a. & It is by coincidence that Academic Medicine (research, education, service) occurs here \\
b. & Research and education are never compromised by clinical workload. \\
c. & We have sufficient funding for research, education and clinical service. \\
d. & Our structures, processes and systems are effective for Academic Medicine to happen. \\
\hline
\end{tabular}

Definitions of Positive, Neutral \& Negative:

(1) Positive response refers to responses that were rated a 4 or 5 (Agree/Strongly Agree) for positively worded questions, or a 1 or 2 (Disagree/Strongly Disagree) for negatively worded questions.

(2) Neutral response refers to responses that were rated a 3 (Neither or Sometimes) for any question.

(3) Negative response refers to responses that were rated a 1 or 2 (Disagree/Strongly Disagree) for positively worded questions, or a 4 or 5 (Agree/Strongly Agree) for negatively worded questions.

For each dimension, the total number of response items (T) is the number of respondents multiplied by four as each dimension has 4 questions. All the positive responses in each dimension were summated and this was divided by the total number of response items (T) to give the percentage of positive responses of each dimension for each year. Pearson chi-square analysis was performed to compare the number of positive and non-positive responses within each dimension overall across the years (2011, 2012 $\&$ 2013) and pairwise (2011 vs. 2012; 2012 vs. 2013; 2011 vs. 2013). Statistical significance is reached when $p<.05$.

In addition, to compare between junior and senior physicians, the respondents were divided to the 2 categories of junior and senior physicians. For each category \& each dimension, the total number of response items $(\mathrm{T})$ is the number of respondents multiplied by four as each dimension has 4 questions. All the positive responses in each dimension were summated and this was divided by the total number of response items (T) to give the percentage of positive responses of each dimension for each year. Pearson chi-square

Published by Sciedu Press analysis was performed to compare the number of positive and non-positive responses within each dimension between years $2011 \& 2013$. Statistical significance is reached when $p<.05$.

SPSS statistical software version 19.0 were used to analyse survey data. Qualitative comments were also sought in the surveys.

\section{RESULTS}

A total of 82 staff, comprising $40(78.4 \%)$ of the 51 senior physicians and $42(73.7 \%)$ of 57 junior physicians, responded for the first survey. The three top favorable dimensions having the highest percentage of positive response were: Supervisor \& Departmental Support for Academic Medicine (64.0\%); Academic Faculty Development (57.9\%); and Communications \& Feedbacks on Academic Medicine (57.3\%). The bottom three dimensions were: Academic Clinical Staffing (23.8\%); Relating Clinical Service to Research and Education (33.2\%) and Academic Teamwork across Institutions (36.3\%) (Refer to Table 3 and Figure 1).

The top three favorable questions were: Faculty development is important for professional growth (89.0\%); My supervisor/head gives an encouraging word/signal when he/she sees a job relating to Academic Medicine (75.6\%); We are updated about academic changes in our department (75.3\%). The least positive responded questions were: We have enough staff to handle the department clinical and academic workload (17.1\%); Academic Medicine is never compromised when more clinical work needs to be done (18.3\%); We have sufficient staff to cope with the department's clinical and academic workload (22.0\%); Protected time for faculty development and learning is problematic for staff in this hospital (22.0\%). 
Table 3. Academic medicine culture dimensions surveyed in study

\begin{tabular}{|c|c|c|c|c|c|c|c|}
\hline \multirow{2}{*}{$\begin{array}{l}\text { Academic Medicine Culture } \\
\text { Dimensions }\end{array}$} & \multicolumn{3}{|c|}{ Survey } & \multicolumn{4}{|c|}{$p$-value } \\
\hline & $\begin{array}{l}2011 \\
(n=82, T=328)\end{array}$ & $\begin{array}{l}2012 \\
(n=105, T=420)\end{array}$ & $\begin{array}{l}2013 \\
(n=71, T=284)\end{array}$ & $\begin{array}{l}\text { Difference } \\
\text { (2011 vs. 2012) }\end{array}$ & $\begin{array}{l}\text { Difference } \\
\text { (2012 vs. 2013) }\end{array}$ & $\begin{array}{l}\text { Difference } \\
\text { (2011 vs .2013) }\end{array}$ & $\begin{array}{l}\text { Overall } \\
\text { Difference }\end{array}$ \\
\hline $\begin{array}{l}\text { 1. Leadership \& Management } \\
\text { Support for Academic Medicine }\end{array}$ & $\begin{array}{l}165 \\
(50.3 \%)\end{array}$ & $\begin{array}{l}241 \\
(57.5 \%)\end{array}$ & $\begin{array}{l}214 \\
(75.4 \%)\end{array}$ & $.050^{*}$ & $<.001^{*}$ & $<.001^{*}$ & $<.001^{*}$ \\
\hline $\begin{array}{l}\text { 2. Supervisor and Departmental } \\
\text { Support for Academic Medicine }\end{array}$ & $\begin{array}{l}210 \\
(64.0 \%)\end{array}$ & $\begin{array}{l}256 \\
(61.0 \%)\end{array}$ & $\begin{array}{l}210 \\
(73.9 \%)\end{array}$ & .390 & $<.001^{*}$ & $.008^{*}$ & $.001^{*}$ \\
\hline $\begin{array}{l}\text { 3. Communications \& Feedbacks } \\
\text { on Academic Medicine }\end{array}$ & $\begin{array}{l}188 \\
(57.3 \%)\end{array}$ & $\begin{array}{l}259 \\
(62.3 \%)\end{array}$ & $\begin{array}{l}209 \\
(73.6 \%)\end{array}$ & .172 & $.002^{*}$ & $<.001^{*}$ & $<.001^{*}$ \\
\hline $\begin{array}{l}\text { 4. Learning \& Innovation } \\
\text { Environment }\end{array}$ & $\begin{array}{l}163 \\
(49.7 \%)\end{array}$ & $\begin{array}{l}232 \\
(55.2 \%)\end{array}$ & $\begin{array}{l}189 \\
(66.5 \%)\end{array}$ & .132 & $.003^{*}$ & $<.001^{*}$ & $<.001^{*}$ \\
\hline 5. Academic Scholarly Activities & $\begin{array}{l}157 \\
(47.9 \%)\end{array}$ & $\begin{array}{l}245 \\
(58.3 \%)\end{array}$ & $\begin{array}{l}207 \\
(72.9 \%)\end{array}$ & $.004^{*}$ & $<.001^{*}$ & $<.001^{*}$ & $<.001^{*}$ \\
\hline $\begin{array}{l}\text { 6. Academic Faculty } \\
\text { Development }\end{array}$ & $\begin{array}{l}196 \\
(59.8 \%)\end{array}$ & $\begin{array}{l}261 \\
(62.1 \%)\end{array}$ & $\begin{array}{l}209 \\
(73.6 \%)\end{array}$ & .506 & $.002^{*}$ & $<.001^{*}$ & $.001^{*}$ \\
\hline $\begin{array}{l}\text { 7. Academic Teamwork Within } \\
\text { Institution/Hospital }\end{array}$ & $\begin{array}{l}174 \\
(53.0 \%)\end{array}$ & $\begin{array}{l}260 \\
(61.9 \%)\end{array}$ & $\begin{array}{l}210 \\
(73.9 \%)\end{array}$ & $.015^{*}$ & $.001^{*}$ & $<.001^{*}$ & $<.001^{*}$ \\
\hline $\begin{array}{l}\text { 8. Academic Teamwork Across } \\
\text { Institutions }\end{array}$ & $\begin{array}{l}113 \\
(34.5 \%)\end{array}$ & $\begin{array}{l}200 \\
(47.6 \%)\end{array}$ & $\begin{array}{l}168 \\
(59.2 \%)\end{array}$ & $<.001^{*}$ & $.003^{*}$ & $<.001^{*}$ & $<.001^{*}$ \\
\hline $\begin{array}{l}\text { 9. Relating Clinical Service to } \\
\text { Research \& Education }\end{array}$ & $\begin{array}{l}110 \\
(33.5 \%)\end{array}$ & $\begin{array}{l}180 \\
(42.9 \%)\end{array}$ & $\begin{array}{l}177 \\
(62.3 \%)\end{array}$ & $.009^{*}$ & $<.001^{*}$ & $<.001^{*}$ & $<.001^{*}$ \\
\hline 10. Academic Clinical Staffing & $\begin{array}{l}94 \\
(28.7 \%)\end{array}$ & $\begin{array}{l}143 \\
(34.0 \%)\end{array}$ & $\begin{array}{l}149 \\
(52.5 \%)\end{array}$ & .116 & $<.001^{*}$ & $<.001^{*}$ & $<.001^{*}$ \\
\hline $\begin{array}{l}\text { 11. Satisfaction \& Remuneration } \\
\text { for Academic Medicine }\end{array}$ & $\begin{array}{l}142 \\
(43.3 \%)\end{array}$ & $\begin{array}{l}205 \\
(48.8 \%)\end{array}$ & $\begin{array}{l}173 \\
(60.9 \%)\end{array}$ & .133 & $.002^{*}$ & $<.001^{*}$ & $<.001^{*}$ \\
\hline 12. Organizational Learning & $\begin{array}{l}171 \\
(52.1 \%)\end{array}$ & $\begin{array}{l}261 \\
(62.1 \%)\end{array}$ & $\begin{array}{l}173 \\
(60.9 \%)\end{array}$ & $.006^{*}$ & .742 & .029 & $.015^{*}$ \\
\hline $\begin{array}{l}\text { 13. Overall Perceptions of } \\
\text { Academic Medicine }\end{array}$ & $\begin{array}{l}134 \\
(40.9 \%)\end{array}$ & $\begin{array}{l}190 \\
(45.2 \%)\end{array}$ & $\begin{array}{l}194 \\
(68.3 \%)\end{array}$ & .230 & $<.001^{*}$ & $<.001^{*}$ & $<.001^{*}$ \\
\hline
\end{tabular}

Based on the first survey, several initiatives were launched or enhanced. These included introduction of protected educational \& research time as well as appropriate service backfill for clinical care. Physicians to provide service needs like Service Registrars were recruited for dedicated clinical care as backfill. Nurses were also trained to take more-expanded clinical roles in patient care e.g. Nurse Residents.

In the second survey, a total of 43 out of $49(87.8 \%)$ senior physicians and 62 out of 78 (79.5\%) junior physicians responded to the survey. There was overall improvement in 12 out of the 13 dimensions surveyed. There were significant improvements in areas involving Academic Teamwork across Institutions, Academic Scholarly Work and Organizational Learning. The lowest-scoring dimension in the first survey, Academic Staffing Issue also showed improvement (see Figure 1). While there was improvement of positive responses of junior doctors for all the dimensions, there was only improvement of positive responses of senior doctors for six of the dimensions only (see Figure 2).

In the third survey held two year later from the first survey, a total of 34 out of 47 (72.3\%) senior physicians and 37 out of $72(51.3 \%)$ junior physicians responded to the survey. Compared to the second survey, 12 out of the 13 dimensions in Academic Medicine culture showed overall improvement. When compared to the first survey, there was overall improvement for all 13 dimensions. There was improvement of positive responses of both junior and senior doctors for all the 13 dimensions as well (see Figure 2).

The qualitative comments also reflected the positive change in the quantitative responses of the surveys over the 3 years. There were many negative comments in the first survey. Examples of such comments were: "it has always been a struggle to find dedicated time for research or teaching due to requirements for clinical service"; "there's less availability of additional manpower coverage to allow dedicated time for academic activities"; "it seems like much of what we do at our department is based upon protocols and dogma, not on evidence based medicine, which should be the foundation of academic medicine"; and "the idea of academic medicine is attractive but we are still in its infancy. Development in right direction but a lot more can be done - more integration, collaborative... Also concern sometimes more talk than real action".

In the later surveys, there were less negative feedbacks and comments were increasingly positive. Examples of such comments were: "I feel very happy to see the encouragement I get here for doing academic work. With continued support we can further raise the overall benchmark for education"; "Looking forward for better progress in AM!"; "ACP is a good complement to the clinical aspect of the hospital as it allows for better evidence-based medical practice"; and "the OBGYN Department has an excellent teaching faculty and 
kind mentors. There is enough time to receive as well as impart knowledge, without compromising patient care. In fact, I feel that academic medicine optimizes and enhances patient care by allowing us to practise evidence based medicine. Women's health issues deserve center-stage in today's global health agenda and a world-class OBGYN center needs to be able to provide up-to-date care for women - not just with research and new innovations, but also with the guidance of experienced and learned mentors. I think the department has done a very good job in this aspect".

In the surveys, there were faculty and staff understanding of the difficult challenges of changing to an academic culture. Examples of comments were: "This is a long journey ahead but we have the talent, infrastructure and commitment to be a top-notched academic medical center" and "I think it will be a difficult process to change, but a beneficial one in the long run”.

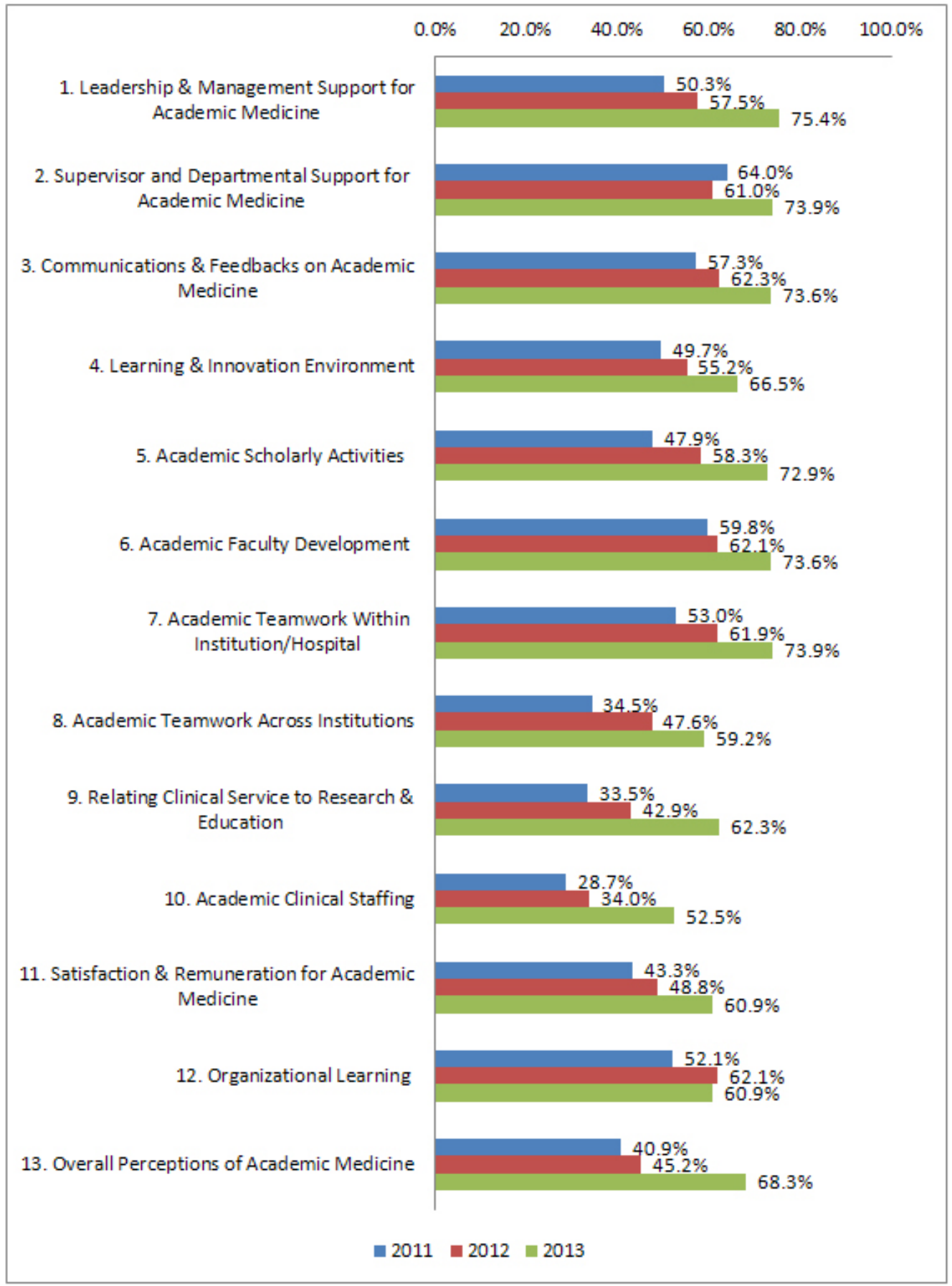

Figure 1. OBGYN ACP Academic Medicine Culture percentage of positive responses in each dimension (2011-2013) 


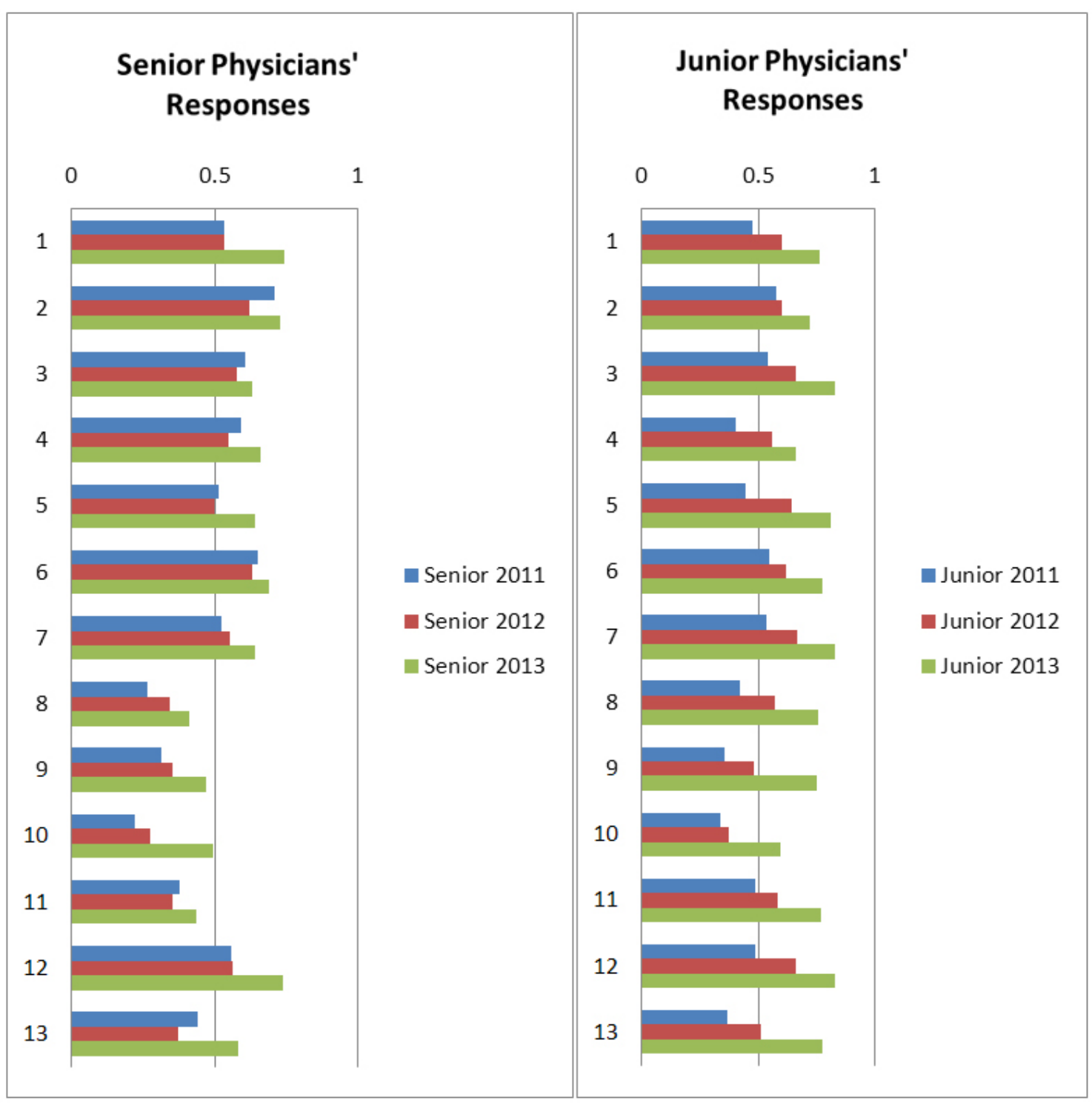

Figure 2. Comparison of the positive responses of senior \& junior physicians

For junior physicians, all dimensions scores reflected improvements from 2011 to 2013. All increments of 2013 compared to 2011 were statistically significant, $p<.05$;

For senior physicians, all dimensions scores reflected improvements from 2011 to 2013. Comparing 2013 with 2011, increments in eight dimensions $(1,5,7,8,9,10,12 \& 13)$ reached statistically significance, $p<.05$;

Sample sizes of each year's survey:

(1) Year $2011=82$ (40 Senior Physicians and 42 Junior Physicians)

(2) Year $2012=105$ (43 Senior Physicians and 62 Junior Physicians)

(3) Year $2013=71$ (34 Senior Physicians and 37 Junior Physicians)

\section{Discussion}

The thirteen dimensions identified from focused group discussions, relate to the culture, enablers and barriers of academic medicine. These dimensions were derived and distilled from faculty feedbacks and discussions of the various published conceptual frameworks, themes or models which look at enablers and barriers of academic medicine and faculty development. Yap $\mathrm{HK}^{[8]}$ emphasized protected time, sabbatical leave \& financial support to attend professional conferences and to initiate research protocols; as essential ingredients for faculty development in academic medicine. Development of programmes for the training of clinicianscientists is also important. Daley ${ }^{[9]}$ identified access and support of senior faculty mentors, peer networking, professional skill development, and knowledge of institutional culture for success in academic medicine. Wong $\mathrm{JE}^{[10]}$ emphasized the need for a formal Track system with protected time for clinician scholars and clinician scientists and providing 
staff with the appropriate incentives that drive quality and productivity.

The enablers proposed by Krishan $\& \mathrm{Ng}^{[11]}$ for propelling academic medicine from vision to reality were vibrant functional ecosystem, shared vision and mission, right leadership, establishment of good organisational structures, accountability by incentivising performance, communications between faculty and management, platforms that provide resources $\&$ faculty development and academic titles \& recognition. In transformational framework of Academic Medicine Education Institute $(\mathrm{AM} \bullet E I)$ of SingHealth Duke-NUS Academic Medical Centre (AMC), faculty development, development of a community of educators, recognition for educational efforts, institutional support, and better communication about educational activities were key to success in academic medicine ${ }^{[12]}$ Dzau et al. highlighted the need for transformation organization change and the need for collaborative external partnerships. ${ }^{[13]}$

Our study provided a perspective to academic medicine culture and was to our knowledge, the first study to perform on a group of health care practitioners in Asia on their attitudes and views on the culture, enablers and barriers of Academic Medicine within their settings.

Two differing organizational cultures (SingHealth, a clinical enterprise and Duke-NUS, a medical school) took on a common mission in Academic Medicine to improve patients' lives. This joint partnership evolved to the SingHealth Duke-NUS AMC in 2015 and the second AMC in Singapore, of which the first AMC is the National University Health System. ${ }^{[14]}$ Our ACP is a cluster-wide framework for each clinical specialty to advance in Academic Medicine, with resources and funding support from SingHealth and DukeNUS ${ }^{[11]}$ Each ACP is designed based on a clinical discipline and brings together all specialists in the discipline in separate departments across various institutions for greater synergies in clinical care, education and research.

Our surveys have given us insights into faculty's views and beliefs. It helped us to better engage our faculty in realizing our Academic Medicine Vision and has guided us on how to best enhance our academic medicine culture and reduce barriers. The response rate was high for the first and second study due to the use of reminder. In the third study, the response rate was lower as reminder emails were not sent.

Academic Medicine and the curiosity that is engendered by this scholarly environment, coupled with the right resources, and key drivers, can produce clinical breakthroughs that lead to new and better treatments. ${ }^{[13]}$ Faculty development for healthcare professionals is regarded as essential to enhanc- ing teaching effectiveness and medical education. ${ }^{[16,17]}$ The relevant dimensions, namely Academic Scholarly Activities, Academic Faculty Development and Organizational Learning showed improvement in perception in our survey.

Clinician educators, researchers \& scientists should be given the opportunity to work with professional groups across different disciplines to achieve excellence. The relevant survey dimensions, Learning \& Innovation Environment, Academic Teamwork Within Institution/Hospital and Academic Teamwork Across Institutions, also showed improvement in our surveys. Optimal teamwork within departments and with other institutions can enhance the standard of research and education.

AMCs can attract and retain top talent in the healthcare industry. It is a well-known fact that in USA, AMCs are able to attract \& retain the "best" physicians while offering reasonable pay packages. ${ }^{[13]}$ AMCs give physicians the intellectual freedom and support to quench their academic thirst. AMCs also help them to teach and to respond to unmet needs and unanswered questions that in turn, allow physicians to improve care for their patients. The relevant dimensions, namely, Relating Clinical Service to Research \& Education, Academic Clinical Staffing and Satisfaction \& Remuneration for Academic Medicine, though among the lowest in positive perception showed improvement. To solve complex problems, adequate resources and funding are paramount and these need to be appreciated by the funding sources.

Academic medicine pursuit supports three missions of clinical excellence, education, and research. However, the nature of the 3 missions can sometimes cause a rift in faculty members whose interests both conflict and compete with each other. Addressing them, requires effective communications between faculty and management from both entities. Clearing the air on faculty's roles, devising viable academic career paths in the AMC, providing a comprehensive overview of the resources \& support for our faculty, can ensure a deeper staff understanding of our ecosystem and enhance the synergy of the 3 missions.

While Communications \& Feedbacks on Academic Medicine and Leadership \& Management Support for Academic Medicine dimensions increased significantly, Supervisor and Departmental Support for Academic Medicine showed a slight decrease in the second survey but increased at the third survey. This could be attributed to the fact that while there was an initial rapid increase in the junior staffing level from the initiatives of the program, the senior doctor staffing level did not increase correspondingly and thus the supervisory capacity was stretched. It is important to engage and support the staff in the academic medicine setting, as negative 
perceptions (unrelatedness and lack of engagement) were associated with leaving due to dissatisfaction. ${ }^{[18]}$

The higher positive perception in the subsequent surveys was likely as a result of changes we made within the system. Several initiatives were launched or enhanced. ${ }^{[19]}$ The least positive issues identified in the initial survey were insufficient staff to cope with the department's clinical \& academic workload and lack of protected time for faculty development. These were thus given priority by the leadership. Initiatives launched to address them included provision of adequate service backfill for clinical work and provision of protected research and educational time.

Physicians to provide service needs e.g. Service Registrars, were recruited for dedicated clinical care. There was a concerted active recruitment effort by the OBGYN ACP department and the hospital. The recruitment was successful with the hire of a few service registrars \& clinical associates and these physicians relieved the very busy workload in the department and allowed the department to give faculty protected time for academic and scholarly activities. A night float roster system was introduced ${ }^{[20]}$ and was enhanced with higher intake of residents. The arrangement of night calls in each month allowed the junior physicians to have adequate rest. The reduction of fatigue contributed to the increased enthusiasm amongst the junior doctors in learning. ${ }^{[20]}$

An Evidence-Based Medicine Practice Workflow Improvement committee was set up in the ACP and this helped to streamline work processes to ensure efficiency and safety. Training seminars were also conducted by the committee to familiarize faculty with the new processes which enabled clinical service areas to be run efficiently. At the same time, nurses were engaged to take more responsibility and roles in patient care. Nurses were trained to take more-expanded clinical roles in patient care through the Nurse Resident Program. OBGYN ACP department together with the nursing division in the hospital created this structured program where nurses were up-skilled to competently perform tasks usually done by junior physicians e.g. venipuncture, setting drips and clerking of non-complicated patients. The program was very well received. There were few batches of Nurse Residents trained and they helped to relieve the load of junior physicians for them to have time for scholarly activities while improving satisfaction for nurses to perform at a higher level.

ACP Grant Awards were established to promote clinical and translational research among junior physicians and residents within the OBGYN ACP, guided by senior faculty. While these awards are generally small scale (equivalent to USD 3,000-10,000) and about five were awarded each year, they spurred junior and senior faculty to work together, to present at various forums and to have pilot data to compete for bigger grants at national level. Junior physicians were also strongly encouraged and allowed opportunities to teach medical students - a change which has received much positive feedback. A system to facilitate and co-ordinate junior physicians to teach medical students, was initiated. Part of the assessment of junior physicians included assessment of their teaching of medical students. The program was well received by the medical students and junior physicians. Senior physicians also liked it as this initiative help to reduce their load and to enhance teaching in the two hospitals. The initiatives were also in line with changes made to strengthen our Residency program.

The ACP leadership also brought students, junior and senior faculty together and create opportunities for them to network and work together, in many events. These were achieved by creating academic forums \& various platforms. Annual ACP events were started since 2011: OBGYN ACP Research Day, OBGYN ACP Education Day, OBGYN ACP Clinical Practice \& Quality Improvement Day and OBGYN ACP Strategic Academic Retreat. These events enhanced understanding and collaborations within our ACP department.

Underlying the success of these initiatives was the need for prompt and effective communication by the leadership, of not just the initiatives but also the vision. Several town-halls were conducted to communicate the Academic Medicine vision as well as the initiatives and changes. There were high visibility of information of ACP academic vision initiatives and events in the hospital's physical environment and intranet. The ACP set up a Positive Energy and Engagement Reporting (PEER) mechanism as part of its administrative function to track and highlight any positive news in the ACP, especially those related to Academic Medicine. A small win or a positive news item is promptly highlighted in meetings and by emails sent to all faculty in the ACP and celebrated in meetings. These boosted morale and generate motivation for faculty to proceed in the academic medicine journey as they could see and feel the progression.

The ACP also optimized its funding to carry out effective programs while ensuring sustainability. Besides its usual funding sources within the department and hospital, the ACP actively explored with grant opportunities at the AMC and national levels. Philanthropy development, hitherto undeveloped was initiated as this allowed for greater support for the ACP programs. Collaboration between institutions was enhanced with supports from these funding. Two successful examples were SingHealth Duke-NUS AMC grants awarded for development of a regional obstetric emergency training program and the development of an international 
endometriosis network. The regional obstetric emergency training program allowed international collaboration to train the trainers and attracted local and regional participants for its regular course. The international endometriosis network encouraged research collaboration between centers around the world and produced substantial research output. These multiple relationships helped to attract people $\&$ learners and to enhance inter-institutional collaborations.

Our observation suggested that the positive change involved the junior physicians earlier and that it might take longer and more efforts to change the beliefs of senior physicians. This may reflect younger doctors' greater flexibility to adapt to changes in the system, and could accept them more readily. Senior doctors who are used to the old system may require longer and more efforts to make the necessary adjustment in mindsets and attitudes.

There are some limitations in this study. The identification of the dimensions for the academic culture, enablers and barriers for the survey, is a process which our department took to develop from a clinical to an academic clinical department, and to have the opportunity to improve our academic culture. We understand that the dimensions described here and felt to be important by the faculty and leadership for our new academic department may not be directly or universally applicable to new groups or departments. We suggest for new groups contemplating the change to improve academic culture, to discover and identify the elements of culture, enables and barriers with their own discovery process through feedbacks and focused discussions. We hope that our paper will generate discussion on this aspect of academic medicine culture.

Another limitation of this study is that while reminders were used in the first and second surveys, it was not used in the third survey due to an administrative oversight in a busy department. If a second reminder is performed for the third survey, it is likely that the response rate would be higher or at least equal to the first and second survey. This may likely increase the positive responses for the third survey. When launching several initiatives at the same time it is impossible to say what initiative had an effect on the academic medicine climate. However these initiatives were directly and indirectly related to and derived from the findings in the first survey. Thus the initiatives together could have an effect on the academic cultural climate. There was no control group of another clinical department and the study has only the historical control of our academic department with the serial surveys done annually. The major changes in the department in that time frame were essentially due to the various initiatives that were started arising from the information from the first survey. As there were no other major changes in that time frame that dealt with it, the survey results and its derived initiatives likely play a part in the positive changes of academic culture.

Change management is thus important. The culture of academic medicine needs to evolve in tandem and should be made highly supportive of the diverse staff including both junior and senior faculty. A carefully designed multiinstitutional learning community can transform the way staff experience and view institutional culture as well as motivate and prepare them to be change agents in their own institutions. ${ }^{[21]}$ People, structures, policies, and reward systems must be put into place to support cultural values, and broadbased support should be created in order for changes to persist when transitions occur. ${ }^{[22]}$ Transforming academic medical culture includes embracing a system that supports and rewards tailored individual academic career plans, enhancing recognition for faculty; deepening administrative and team supports; and rewarding mentorship for junior faculty. ${ }^{[23]}$ An engaged leadership can foster robust organizational change and restructuring within an academic health center to support quality and safety of health care with relatively modest incremental financial resources. ${ }^{[24,25]}$ Through these, academic health centers can ensure positive commitment of faculty throughout all stages of their careers.

Based on our surveys over the 3 years, there were positive perception changes in academic medicine culture for both senior \& junior physicians, likely arising from initiatives within the department to engage staff and to change the academic medicine culture. These multi-dimensional structured surveys have been useful to evaluate the progress of our initiatives and to enhance academic medicine culture.

\section{CONFLICTS OF INTEREST Disclosure}

The authors declare they have no conflicts of interest.

\section{REFERENCES}

[1] Haizlip J, May N, Schorling J, et al. Perspective: the negativity bias, medical education, and the culture of academic medicine: why culture change is hard. Acad Med. 2012; 87(9): 1205-9.
PMid: 22836850. http://dx.doi.org/10.1097/ACM.0b013e3 $182628 f 03$

[2] Hellings J, Schrooten W, Klazinga NS, et al. Improving patient safety culture. Int J Health Care Qual Assur. 2010; 23(5): 489-506. 
PMid: 20845679. http://dx.doi.org/10.1108/09526861011 050529

[3] Mannion R, Konteh FH, Davies HT. Assessing organisational culture for quality and safety improvement: a national survey of tools and tool use. Qual Saf Health Care. 2009; 18(2): 153-6. PMid: 19342532. http://dx.doi.org/10.1136/qshc. 2007.024075

[4] Sorra J, Gray L, Streagle S, et al. AHRQ Hospital Survey on Patient Safety Culture: User's Guide. (Prepared by Westat, under Contract No. HHSA290201300003C). AHRQ Publication No 15-0049-EF (Replaces 04-0041). Rockville, MD: Agency for Healthcare Research and Quality. January 2016. Available From: http://www .ahrq.gov/professionals/quality-patient -safety/patientsafetyculture/hospital/index.html

[5] Pololi LH, Kern DE, Carr P, et al. The culture of academic medicine: faculty perceptions of the lack of alignment between individual and institutional values. J Gen Intern Med. 2009; 24(12): 128995. PMid: 19834773. http://dx.doi.org/10.1007/s11606-0 09-1131-5

[6] Valantine H, Sandborg CI. Changing the culture of academic medicine to eliminate the gender leadership gap: $50 / 50$ by 2020 Acad Med. 2013; 88(10): 1411-3. PMid: 23969359. http://dx.d oi.org/10.1097/ACM.0b013e3182a34952

[7] Pololi L, Conrad P, Knight S, et al. A study of the relational aspects of the culture of academic medicine. Acad Med. 2009 Jan; 84(1): 106-14. PMid: 19116486. http://dx.doi.org/10.1097/ACM. 0 b013e3181900efc

[8] Yap HK. Academic medicine in Singapore. Ann Acad Med Singapore. 1998 Nov; 27(6): 757-8. PMid: 10101543.

[9] Daley SP, Broyles SL, Rivera LM, et al. A conceptual model for faculty development in academic medicine: the underrepresented minority faculty experience. J Natl Med Assoc. 2011 Sep-Oct; 103(910): 816-21. http://dx.doi.org/10.1016/S0027-9684(15)3 0435-1

[10] Wong JE. The future of medical education: the second 100 years. Ann Acad Med Singapore. 2005 Jul; 34(6): 166C-171C. PMid: 16010402

[11] Krishnan RR, Ng I. Academic medicine: vision to reality. Ann Acad Med Singapore. 2013 Jan; 42(1): 2-4. PMid: 23417584.

[12] Goh SH, Tan KH, Kamei RK, et al. Academic Medicine Education Institute (AM•EI): Transforming the Educational Culture of Health Professionals. Ann Acad Med Singapore. 2015 May; 45(5): 172-7.

[13] Dzau VJ, Ackerly DC, Sutton-Wallace P, et al. The role of academic health science systems in the transformation of medicine. Lancet. 2010; 375(9718): 949-53. http://dx.doi.org/10.1016/S0140 $-6736(09) 61082-5$

[14] National University of Singapore. Creating an academic medical centre of impact. Talk on 22 November 2013 at NUH Weekly Grand Round by Professor Tan Chorh Chuan. NUS News. Published: 27 November 2013. Available from: http://news.nus.edu.sg/highlights/7064-creating-a $\mathrm{n}$-academic-medical-centre-of-impact
[15] Klingle RS, Burgoon M, Afifi W, et al. Rethinking how to measure organizational culture in the hospital setting. The Hospital Culture Scale. Eval Health Prof. 1995 Jun; 18(2): 166-86. PMid: 10143010. http://dx.doi.org/10.1177/016327879501800205

[16] Leslie K, Baker L, Egan-Lee E, et al. Advancing faculty development in medical education: a systematic review. Acad Med. 2013; 88(7): 1038-45. PMid: 23702523. http://dx.doi.org/10.1097/ACM $.0 \mathrm{~b} 013 \mathrm{e} 318294 \mathrm{fd} 29$

[17] Steinert Y, Mann K, Centeno A, et al. A systematic review of faculty development initiatives designed to improve teaching effectiveness in medical education: BEME Guide No. 8. Med Teach. 2006; 28(6): 497-526. PMid: 17074699. http://dx.doi.org/10.1080/014 21590600902976

[18] Pololi LH, Krupat E, Civian JT, et al. Why are a quarter of faculty considering leaving academic medicine? A study of their perceptions of institutional culture and intentions to leave at 26 representative U.S. medical schools. Acad Med. 2012; 87(7): 859-69. PMid: 22622213. http://dx.doi.org/10.1097/ACM. 0b013e3182582b18

[19] Tagore S, Chern B, Goh SL, et al. Specialist training in obstetrics and gynecology in Singapore: transition to structured residency program. J Grad Med Educ. 2012; 4(2): 272-5. PMid: 23730460. http://dx.doi.org/10.4300/JGME-04-02-34

[20] Goh SL, Chern B, Ng MJ, et al. Introduction of the Night Float System in OBGYN Residency Program. Singapore Journal of Obstetrics and Gynaecology. 2013; 44(1): 10-14.

[21] Pololi LH, Krupat E, Schnell ER, et al. Preparing culture change agents for academic medicine in a multi-institutional consortium: the C - change learning action network. J Contin Educ Health Prof. 2013; 33(4): 244-57. PMid: 24347103. http://dx.doi.org/10.1002 /chp. 21189

[22] Krupat E, Pololi L, Schnell ER, et al. Changing the culture of academic medicine: the $\mathrm{C}$-Change learning action network and its impact at participating medical schools. Acad Med. 2013; 88(9): 1252-8. PMid: 23887002. http://dx.doi.org/10.1097/ACM. 0b013e3 $1829 \mathrm{e} 84 \mathrm{e} 0$

[23] Pati S, Reum J, Conant E, et al. Tradition meets innovation: transforming academic medical culture at the University of Pennsylvania's Perelman School of Medicine. Acad Med. 2013; 88(4): 461-4. PMid: 23425986. http://dx.doi.org/10.1097/ACM. 0b013e3 $182857 \mathrm{f} 67$

[24] Bohmer RM, Bloom JD, Mort EA, et al. Restructuring within an academic health center to support quality and safety: the development of the Center for Quality and Safety at the Massachusetts General Hospital. Acad Med. 2009; 84(12): 1663-71. PMid: 19940570. http://dx.doi.org/10.1097/ACM. 0b013e3181bfd09b

[25] Ovseiko PV, Melham K, Fowler J, et al. Organisational culture and post-merger integration in an academic health centre: a mixedmethods study. BMC Health Serv Res. 2015 Jan 22; 15: 25. PMid: 25608775. http://dx.doi.org/10.1186/s12913-014 $-0673-3$ 